\title{
Effects of diabetic education on blood pressure, blood urea, creatinine and fasting sugarby diabetic patients in central hospital Nampula
}

\author{
Article by Madhumati Varma \\ Ph.D in Medicine by Research in Diabetology, India \\ Email: madhumativarma@gmail.com
}

\begin{abstract}
Background: The Global report from the World Health Organization (WHO), published in 2016, estimated that 422 million of the adult population lives with diabetes the number of diabetic patients has dramatically increased 4 times over in the adult population.

Methods: This is Interventional study, 648 of the participants of diabetes mellitus in outpatient diabetic clinic in hospital central Nampula, the participants taken according to inclusion and exclusion criteria, completed the pre-test at baseline and post-test after the second follow up session of education, during each session of education blood pressure, urea, creatinine were recorded. Education commenced with instruction in groups of each session followed by individual advice sessions for each patient with different specialists.

Results: The present study found that educational intervention of diabetes was highly effective to improve blood pressure from baseline mean of 131.02/71.73 $\mathrm{mmHg}$ second follow up 120.95/68.79 $\mathrm{mmHg}$ with standard deviation of baseline $24.35 \mathrm{mmHg} / 14.66 \mathrm{mmHgto}$ second follow up $19.95 \mathrm{mmHg} / 11.33 \mathrm{mmHg}$, blood urea and serum creatinine significantly decreased from baseline in the second follow up $(P<.001)$. A post hoc Turkey test on blood pressure, blood urea and serum creatinine when compared with dependent variable fasting blood sugar found significantly $(P=.05)$ at baseline, at first follow up $(P=.005)$ and at second follow up $(P=.005)$.

Conclusion: The present study found that educational intervention was highly effective in controlling blood pressure, blood urea and creatinine among participants of diabetes mellitus.
\end{abstract}

Keywords: Diabetes Mellitus, blood pressure, blood urea and creatinine, effect education, control, and participants

\section{Introduction}

\section{Background}

\section{Worldwide}

The Global report from the World Health Organization (WHO), published in 2016, estimated that 422 million of the adult population lives with diabetes the number of diabetic patients has dramatically increased 4 times over in the adult population, compared to 108 million in 1980. Diabetes Mellitus is a chronic metabolic disorder, which is caused by partial deficiency or total deficiency of insulin. Diabetic mellitus could be diabetes, which is type 1 complete deficiency of insulin and diabetes type 2, partial deficiency of insulin with receptor of insulin not functioning to facilitate enter glucose into cells for utilization and formation of units of energy. WHO has estimated that the number of diabetic patients will double by 2030 . Diabetes is increasing more rapidly in low and medium income groups than higher income groups as well as in, developing countries compared to European countries, where there is less prevalence of diabetes. The top five countries with the highest prevalence of diabetes. Include the following: India, China, USA, UK, Bazile and Indonesia. Diabetes Type 1 most common in Scandinavian populations, Sardines, and Kuwait, and less common in Asia, Latin and European population. 
Texila International Journal of Medicine

Volume 4, Issue 2, Dec 2016

\section{Mozambique}

Mozambique is located on the East coast of Africa (Wikipedia 2016). There are 274,700 diabetic patients and 9716 deaths due to diabetes, according to a report of 2015 (IDF 2015). This country is the setting for this study. There is the prevalence of obesity, poor knowledge regarding diabetes and lack of awareness of complication of diabetes. Most of the population uses traditional healer for treatment of diabetes. There are unhealthy food habits, sedentary lifestyle in urban population and increased economic growth amongst professions related to office work, which is one of the risk factors that causes diabetes and its complications. There are no professional health, diabetes educators and patients have little or no knowledge of selfmanagement, adherence of treatment, awareness of complication. Among the group of patients who seek care in public hospitals, many are poor and cannot afford the cost of medication or healthy foods. There is an 80 dollar expenditure allotted to each patient of diabetes from the country's Ministry of Health and supported by the government. Additionally, the ministry of health provides free medication for all chronic diseases, including diabetes and hypertension. Currently, there is no study that has been done on the effects of education in various modalities of diabetes for patients and its outcome. Accordingly, there is an extreme need to educate patients of diabetes to improve diabetic control and reduce its complication.

\section{Problem}

The population for this study are diabetic patients in the Central Hospital Nampula in Mozambique, who are from low and medium income groups. This group of patients has limited sources of incomes and, completely depends on the diabetic pharmacological treatment of the government hospital pharmacy, which gives medication free of cost. In the country of Africa, there is a generally poor health education regarding the diabetes. There are no professional diabetic health educators and patients receive advice from doctors and dieticians regarding their diets and directions on how to use their prescriptions of medicine so as to continue treatment at home. Due to the large size of patient loads in outpatient consultations of diabetes, it is not possible to sit with each patient and provide specific health education about diabetes. Also, these groups of patients do not access of the internet to seek their own self-education from different sources. It is clear that when diabetic patients only utilize pharmacological treatments that it is not sufficient to control diabetes and complication (Association, 2002).

\section{Objective}

1. There is a need for lifestyle modification, knowledge of diabetes and its complication, as chronic disease,so that patients can ability to detect small symptoms of complication and present physician, adherence of treatment and its important.

2. There are different types, categories, and levels of controlled diabetic patients and the each type requires different types of education, depending on complications and diseases associated with diabetes.

There following are the clinical categories patients:

1. Good control over blood sugar and without complication.

2. Fair/not controlled blood sugar with or without complication.

3. Good control of blood sugar and without complication, but other disease example HIV treatment, CVA etc.

\section{Question statement}

To conduct the study, used dependent variable fasting blood sugar and independent age, body mass index.

Positive hypothesis, the positive correlation of control of fasting blood sugar change of lifestyle modification includes diet and exercise. The positive correlation with control of fasting blood sugar to blood pressure, blood urea and creatinine. The knowledge of diabetes 
could help in controlling diabetes and blood sugar in case implemented knowledge of diabetes in life style.

Null hypothesis, the diabetes more common with age of 45-60 but not uncontrolled by increase of age. The various reasons which can responsible for uncontrolled fasting blood sugar, in case not implemented knowledge of diabetes in life style.

\section{Assumption and limitation}

There is a need to implement before each consultation of control of diabetes for writing the prescription of medicine and controlling complication. There should be a 15 minute session of education to reemphasized, remember to patients to continue habits which helping to control diabetes. It is seen continues education help to keep continue positive habits to control diabetes. As increase period after education, some of patients come back to the same stage as they were started.

There was limitations as Mozambique is developing country as limited resources in hospital. To minimized expenditure, there are available only fasting blood sugar. There is no concept of doing the regular postprandial blood sugar. There were some time none availability of reagent in the laboratory to evaluate blood sugar, blood urea and creatinine during the period of study. That makes statically results different from which was accepted. To choose topic also forced to see available facility in a public hospital.

\section{Method}

This study was conducted on regular patients of the diabetic outpatient department of the Central Hospital of Nampula. The study investigated the effects of three sessions of the diabetes education program (baseline, first follow-up and second follow-up) on each patient at one-month intervals. The inclusion and exclusion criteria for participation in the education program are listed below.

\section{Inclusion and exclusion criteria for the study}

Table 1. Inclusion and exclusion criteria for the study

\begin{tabular}{ll}
\hline Inclusion criteria & Exclusion criteria \\
\hline Diabetic patients who come for & Participation in previous diabetes education \\
outpatient consultations & programs for more than 3 sessions \\
Mozambican citizen & Not willing to participate \\
Any age & Live in a location that makes them unable to \\
& return every month for control \\
\hline
\end{tabular}

\section{Sample number and characteristics}

A sample of 648 participants was taken for this study. The inclusion criteria for participating in the diabetes education program dictated that patients should be in the OPD, willing to participate in the education sessions and willing to give consent to be included in the study. Participants were excluded if they had already completed three sessions of education or if they lived in a district that made it impossible for them to return within one month for the next education session.

\section{Organization of education sessions}

Amongst the group instructors were a diabetologist, dietician, psychologist, physiotherapist, and diabetic nurse. The following tasks had to be performed before each of the sessions:

\section{The baseline session}

The diabetic nurse took consent and accessed the patient's clinical history before conducting a physical examination that included checking vital signs and fasting blood sugar to blood pressure. The physical examination was to be done by a physician. They also noted 
Texila International Journal of Medicine

Volume 4, Issue 2, Dec 2016

the results of a fasting blood sugar, urea and creatinine analysis that tested, which had been conducted 2-3 days prior to the education session.

\section{First follow up}

At the beginning of the session, the diabetic nurse measured the blood pressureand noted the results of the blood analysis that tested for fasting blood sugar, blood urea and creatinine, which had been conducted 2-3 days prior to the education session. The physicians and other specialists also noted the relevant patient information.

\section{Second follow up}

At the beginning of the session, the diabetic nurse measured the blood pressure and noted the results of the blood analysis that tested for fasting blood sugar, blood urea and creatinine, which had been conducted 2-3 days prior to the education session. The physicians and other specialists also noted the relevant patient information.

\section{Method of education}

The education sessions were in the form of a conference with all specialists leading a class in various verbal forms, demonstrating real situations, operating the relevant apparatus and discussing any difficulties at the end of the session.

\section{Description of health education intervention}

\section{Description of the specialists that participated in giving the education sessions}

The different types of specialists involved in the health education intervention were:

1. The psychologist oriented the patients with basic aspects of psychology to help them live with diabetes.

2. The diabetologist provided knowledge about the general concepts of diabetes.

3. The dietician provided information about the specific diet needed for diabetic patients.

4. The physiotherapist demonstrated important exercises that were specifically for sufferers of diabetes and were applicable to all individuals.

\section{Group and individual education sessions}

After a three-hour group education session, individual outpatient consultations were conducted in different rooms with different specialists. These patients could consult a diabetologist, dietician, physiotherapist, or psychologist individually according to the specific needs of each patient.

\section{Organization of health education sessions}

Due to the shortage of separate spaces large enough to accommodate the number of participants in the baseline, first follow-up and second follow-up, sessions were limited to approximately 40-50 participants. To make education sessions more interesting and effective the beginning of each session was realized with baseline participants followed by first followup participants, and then second follow-up participants were taken for education of diabetes. There was no restriction for participants if they wanted to attend the same session twice.

Each session built upon the knowledge gained in the previous session. The health outcomes of each patient were assessed in outpatient service to monitor the implementation of the knowledge imparted in the education sessions in daily life.

\section{Description of educational materials and information provided}

The topics of the sessions were chosen according to local culture, socioeconomic conditions, beliefs, lifestyle, common complications and associated diseases. The aim was to improve the outcomes for diabetes patients and prevent complications. The information was presented in a manner that the participants could easily understand and would motivate them to implement the new information in their daily lives. 


\section{Thetopics of the diabetes education sessions}

- Definition of diabetes and types of diabetes

- Symptoms of hypo- and hyperglycemia, both complications of diabetes

- Management of diabetes by diet and physical activity

- Psychological assistance

- Brief knowledge of medicines that are available in the pharmacy of the hospital

- Management of hypoglycemic medication

- Complications of diabetes and early detection

- Dental and foot care

- Diabetic control in special situations such as during Ramadan or when travelling

- Blood sugar monitoring using a glucometer

- How and where to inject insulin and how to prevent complications

- How to prevent primary and secondary stages of diabetes

- Participation of family members if willing and/or required

Description of the sequence of the diabetes education sessions In groups:

1. Welcome address to participants from a diabetologist

2. First part of the education session: lessons on diabetes by, taught by a diabetologist

3. Second part of the education session: information on diet and nutrition, taught by a dietician

4. Third part of the education session: information on how to cope psychologically with the disease, taught by a psychologist

5. Fourth part of the education session: the benefits of exercise and demonstrations of general exercises that are applicable to all patients, taught by a physiotherapist

6. Fifth part of the education session: how to inject insulin and use a glucometer, taught by a nurse

\section{On an individual basis:}

7. Sixth part of education session: individual consultations with each patient with a diabetologist, dietician, psychotherapist, or physiotherapist to help participants with particular recommendations based on associated diseases and complications, if needed

\section{Patient interviews}

The patients were interviewed in order to gather the following information:

- Identification details

- Medical history/past clinical history

- Blood pressure, body mass index

- Drug history (type of oral hypoglycemic agents, injectable form antidiabetic agents, drugs to maintain blood pressure and lipids)

- Analysis of fasting blood sugar before each session

- Specific findings, if noted by each specialists

\section{Variables used and their ranges}

\section{Blood pressure (repeated for the baseline, first follow-up, and second follow-up)}

Normal: $<120 / 80 \mathrm{mmHg}$

Pre-hypertension: 121-89 mmHg

Mild: 140/90-159/99 mmHg

Moderate: >160/109 mmHg

Severe: >180/110 mmHg

Information not given 
Texila International Journal of Medicine

Volume 4, Issue 2, Dec 2016

Serum Creatinine (repeated for the baseline, first follow-up, and second follow-up)

Normal creatinine (female): $<115 \mathrm{umol} / \mathrm{l}$

Normal creatinine (male): $<88.4 \mathrm{umol} / \mathrm{l}$

Mild creatinine (female): $115-168 \mathrm{umol} / \mathrm{l}$

Mild creatinine (male): 88.4-168 umol/l

Moderate creatinine (both sexes): 176.8-353umol/l

Severe creatinine (both sexes): > 353.6umol/l

Information not given

Blood Urea (repeated for the baseline, first follow-up, and second follow-up)

Normal blood urea: $1.2-3 \mathrm{mmol} / \mathrm{l}$

Mild blood urea: 3-7 mmol/l

Moderate blood urea: $7-11 \mathrm{mmol} / \mathrm{l}$

Severe blood urea: > $11 \mathrm{mmol} / \mathrm{l}$

Information not given

Fasting blood sugar (repeated for the baseline, first follow-up, and second follow-up)

Hypoglycemic range: $<3.9 \mathrm{mmol} / \mathrm{dl}$

Normal: 4-5.8 mmol/dl

Mild hyperglycemic range: 5.9-11 mmol/dl

Moderate hyperglycemic range: $12-19 \mathrm{mmol} / \mathrm{dl}$

Sever hyperglycemic range: $>20 \mathrm{mmol} / \mathrm{dl}$

Problem with laboratory

Information not given

A Data was analyzed SPSS 17 version, and graphs made in excel software.

Outline of presentation of statically analysis as follows:

\section{A. Descriptive analysis}

1. Frequency and percentage tables of various variables with graphic presentations.

2. Central tendency (Mean), standard deviation (stander scores).

B. Correlation analysis

1. Regression-predictive-ability independent and dependent variable

C. Analyzing difference between groups

1. T-test

2. ANOVA

3. Post hoc Turkey test

4. P-value of less than 0.05 were considered to be significant.

D. Tables and graphs use for results

\section{Results}

A sample of 648 participants was taken for this study. This study was conducted on regular patients of the diabetic outpatient department of the Central Hospital of Nampula. The study investigated the effects of three sessions of the diabetes education program (baseline, first follow-up and second follow-up) on each patient at one-month intervals. The inclusion criteria for participating in the diabetes education program dictated that patients should be in the OPD, willing to participate in the education sessions and willing to give consent to be included in the study. Participants were excluded if they had already completed three sessions of education or if they lived in a district that made it impossible for them to return within one month to the next education session. Amongst the group instructors were a diabetologist, dietician, psychologist, physiotherapist, and diabetic nurse. There were various variables to assess from baseline to second follow up education session. The variables were assessed 
blood pressure, blood urea and creatinine with compare to dependent variable fasting blood sugar of patients of diabetes mellitus.

\section{Descriptive analysis of blood pressure at baseline, first follow up, second follow up}

A sample of 648 patients with diabetes mellitus, those who had participated in educational sessions concerning diabetes mellitus, was taken for study in order to determine the effect of education on improving blood pressure levels in diabetes. The measurement of blood pressure was performed at baseline, at the first follow up and at the second follow up. The results are shown in Table 13, below. Briefly, the percentage of patients with normal $<120 / 80 \mathrm{mmHg}$ increased frombaseline $(40,1 \%)$ to the first follow up $(46.1 \%)$ and decreased at the second follow up (27.2\%). The percentage of patients with severe rang $>180 / 110 \mathrm{mmHg}$ blood pressure were observed to decrease from baseline $(4.2 \%$ to the first follow up and to the second follow up (0.6 \%).

Table 2. Descriptive analysis of blood pressure of at baseline, first follow up and second follow up

\begin{tabular}{|c|c|c|c|c|c|c|}
\hline \multirow[b]{2}{*}{$\begin{array}{l}\text { Ranges of Blood } \\
\text { pressure }\end{array}$} & \multicolumn{2}{|l|}{ Baseline line } & \multicolumn{2}{|c|}{ First fallow up } & \multicolumn{2}{|c|}{ Second follow up } \\
\hline & Frequency & $\begin{array}{l}\text { Percen } \\
\text { tages } \\
\%\end{array}$ & $\begin{array}{l}\text { Frequen } \\
\text { cy }\end{array}$ & $\begin{array}{l}\text { Percenta } \\
\text { ges \% }\end{array}$ & Frequency & $\begin{array}{l}\text { Percent } \\
\text { ages \% }\end{array}$ \\
\hline $\begin{array}{l}\text { Normal<120/80 } \\
\text { mmHg }\end{array}$ & 260 & 40.1 & 299 & 46.1 & 176 & 27.2 \\
\hline $\begin{array}{l}\text { Pre hypertension } \\
\text { 121-89 - } \\
\text { 139/89mmhg }\end{array}$ & 118 & 18.2 & 71 & 11.0 & 53 & 8.2 \\
\hline $\begin{array}{l}\text { Mild-140/90- } \\
\text { 159/99 mmHg }\end{array}$ & 156 & 24.1 & 79 & 12.2 & 48 & 7.4 \\
\hline $\begin{array}{l}\text { Moderate }>160 / 109 \\
\text { mm\hg }\end{array}$ & 56 & 8.6 & 32 & 4.9 & 15 & 2.3 \\
\hline $\begin{array}{l}\text { Sever }>180 / 110 \\
\text { mmHg }\end{array}$ & 27 & 4.2 & 4 & 6 & 4 & .6 \\
\hline Not done & 29 & 4.5 & 161 & 24.8 & 350 & 54.0 \\
\hline Total & 646 & 99.7 & 646 & 99.7 & 646 & 99.7 \\
\hline Missing & 2 & .3 & 2 & .3 & 2 & .3 \\
\hline Total & 648 & 100.0 & 648 & 100.0 & 648 & 100.0 \\
\hline
\end{tabular}

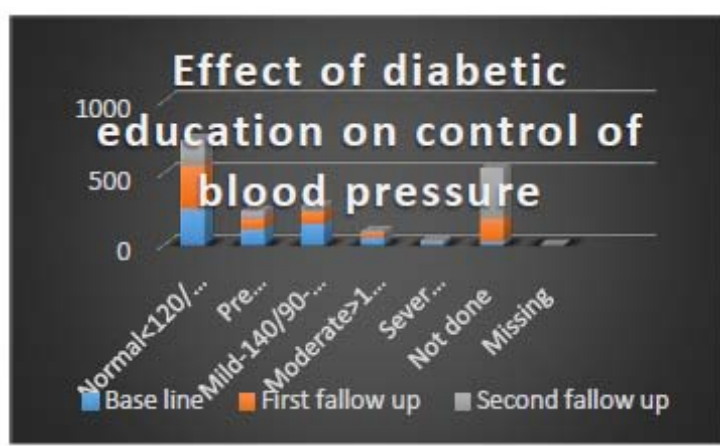

\section{Effect of diabeticn education on control of blood pressure}

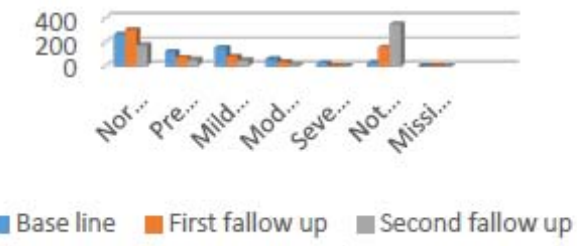




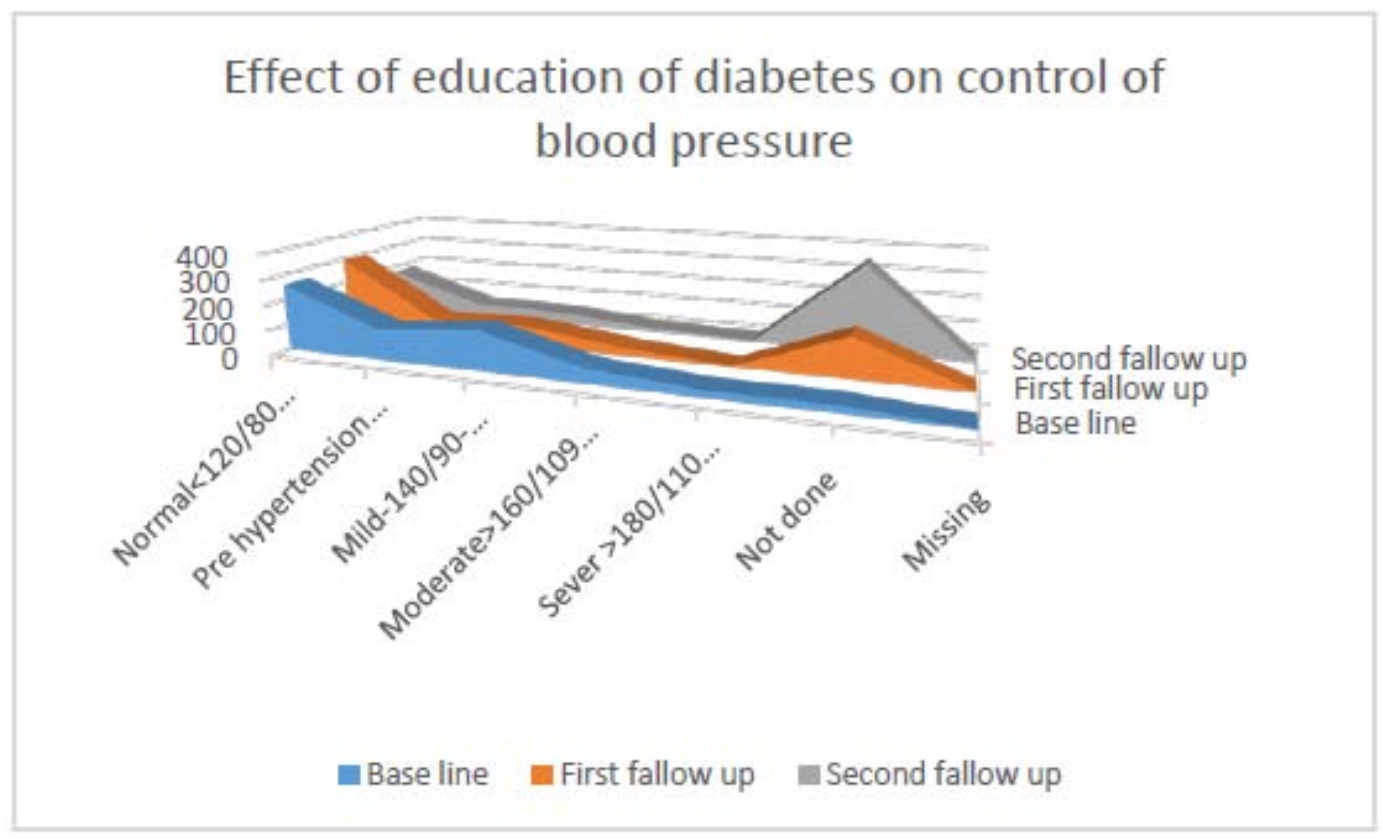

Figures 1. Bar chart and linear chart: In the above charts we see that distribution of the compared blood pressure at baseline, first follow up, and second follow up after diabetes education among participants

\section{Descriptive analysis of blood creatinine concentrations at baseline, first follow up and second follow up}

A sample of 648 patients with diabetes mellitus, who had participated in educational sessions regarding diabetes mellitus, was taken for study in order to determine the effect of education on improving outcomes in diabetes. The analysis for blood creatinine concentration was performed at baseline, at the first follow up and at the second follow up. The results are presented in Table 18, below. Briefly, the percentage of female patients with normal creatinine concentrations of $<115.0 \mathrm{umol} / \mathrm{l}$ decreased from baseline (36.7\%), to the first follow up (31.3\%), to the second follow up (23.1\%). The percentage of male patients with normal creatinine concentrations of $<88.4 \mathrm{umol} / \mathrm{l}$ decreased from baseline $(31.0 \%)$, to the first follow up (24.7\%), to the second follow up (20.4\%). The percentage of female patients with mildly increased creatinine concentrations of 115.0-168.0 umol/l decreased at each follow up from baseline (1.1\%), to the first follow up (1.9\%), to the second follow up (0.6\%). The percentage of male patients with mildly increased creatinine concentrations of 88.4-168.0 umol/l decreased at each follow up from baseline (17.4\%), to the first follow up (15.7\%), to the second follow up (10.0\%). The percentage of patients (male and female) who had moderately increased creatinine concentrations of 176.8-353.0 umol/l decreased at each follow up from baseline (2.2\%), to the first follow up (0.6\%), to the second follow up (0.6\%). The percentage of patients (both male and female) with severely increased creatinine concentrations of $>353.6 \mathrm{umol} / \mathrm{l}$ decreased at each follow up from baseline $(0.5 \%)$, to the first follow up $(0.5 \%)$, to the second follow up $(0.3 \%)$. The percentage of missing values increased from baseline (11.1\%), to the first follow up (25.3\%), to the second follow up (44.9\%). 
Texila International Journal of Medicine Volume 4, Issue 2, Dec 2016

Table 3. Descriptive analysis of serum creatinine at baseline, first follow up and second follow up

\begin{tabular}{|c|c|c|c|c|c|c|}
\hline \multirow[b]{2}{*}{$\begin{array}{l}\text { Ranges of Blood } \\
\text { creatinine }\end{array}$} & \multicolumn{2}{|c|}{ Baseline line } & \multicolumn{2}{|c|}{ First follow up } & \multicolumn{2}{|c|}{ Second follow up } \\
\hline & $\begin{array}{l}\text { Frequenc } \\
\mathrm{y}\end{array}$ & $\begin{array}{l}\text { Percentag } \\
\text { es } \%\end{array}$ & $\begin{array}{l}\text { Frequenc } \\
\mathrm{y}\end{array}$ & $\begin{array}{l}\text { Percentag } \\
\text { es } \%\end{array}$ & $\begin{array}{l}\text { Frequenc } \\
\mathrm{y}\end{array}$ & $\begin{array}{l}\text { Percenta } \\
\text { ges } \%\end{array}$ \\
\hline $\begin{array}{l}\text { Nomal female } \\
\text { creatinine }<115 \mathrm{um} \\
\text { ol/l }\end{array}$ & 238 & 36.7 & 203 & 31.3 & 150 & 23.1 \\
\hline $\begin{array}{l}\text { Normal creatinine } \\
\operatorname{man}<88.4 \text { umol/l }\end{array}$ & 201 & 31.0 & 160 & 24.7 & 132 & 20.4 \\
\hline $\begin{array}{l}\text { Mild creatinine } \\
\text { female 115-168 } \\
\text { umol/l }\end{array}$ & 7 & 1.1 & 12 & 1.9 & 4 & .6 \\
\hline $\begin{array}{l}\text { Mild creatinine } \\
\text { man 88.4-168 } \\
\text { umol/l }\end{array}$ & 113 & 17.4 & 102 & 15.7 & 65 & 10.0 \\
\hline $\begin{array}{l}\text { Moderate } \\
\text { creatinine both } \\
\text { 176.8-353umol/l }\end{array}$ & 14 & 2.2 & 4 & .6 & 4 & 6 \\
\hline $\begin{array}{l}\text { Sever creatinine } \\
\text { both }>353.6 \mathrm{umol} / \mathrm{l}\end{array}$ & 3 & .5 & 3 & .5 & 2 & .3 \\
\hline Not done & 72 & 11.1 & 164 & 25.3 & 291 & 44.9 \\
\hline Total & 648 & 100.0 & 648 & 100.0 & 648 & 100.0 \\
\hline
\end{tabular}
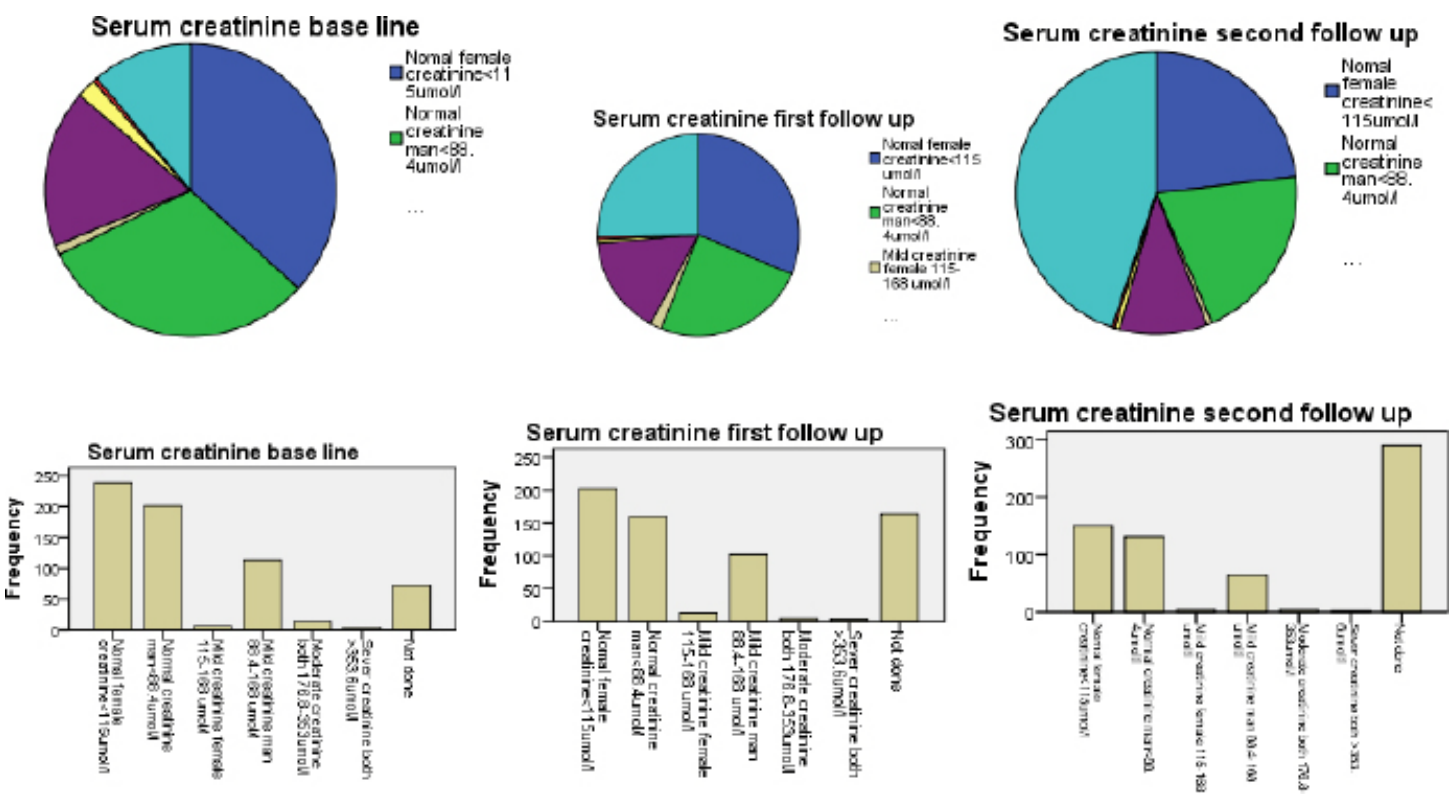
Texila International Journal of Medicine

Volume 4, Issue 2, Dec 2016

\section{Effect of diabetic education on control of s.creatinine}
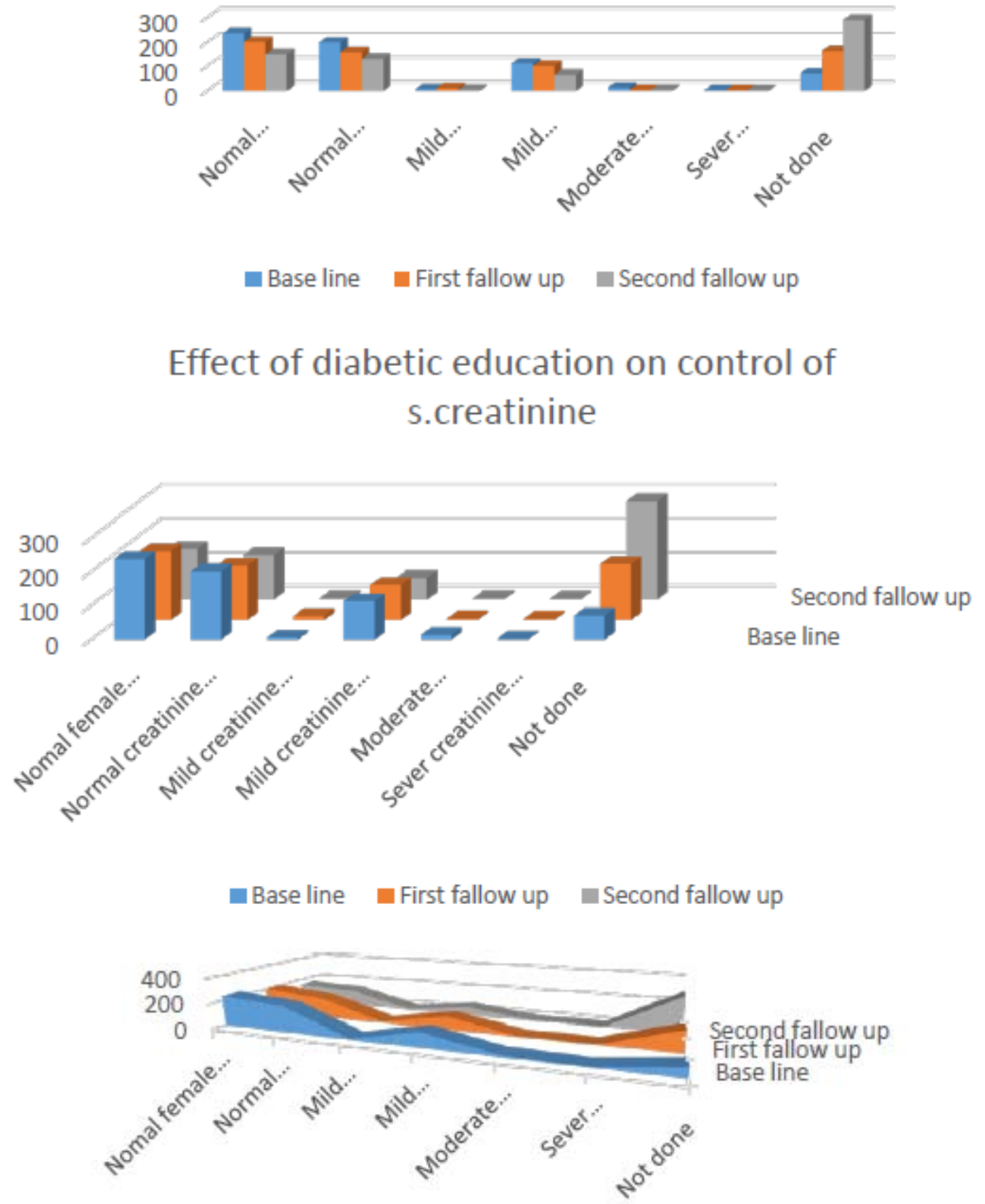

Base line $\quad$ First fallow up Second fallow up 


\section{Creatinine level at different follow up schedule}

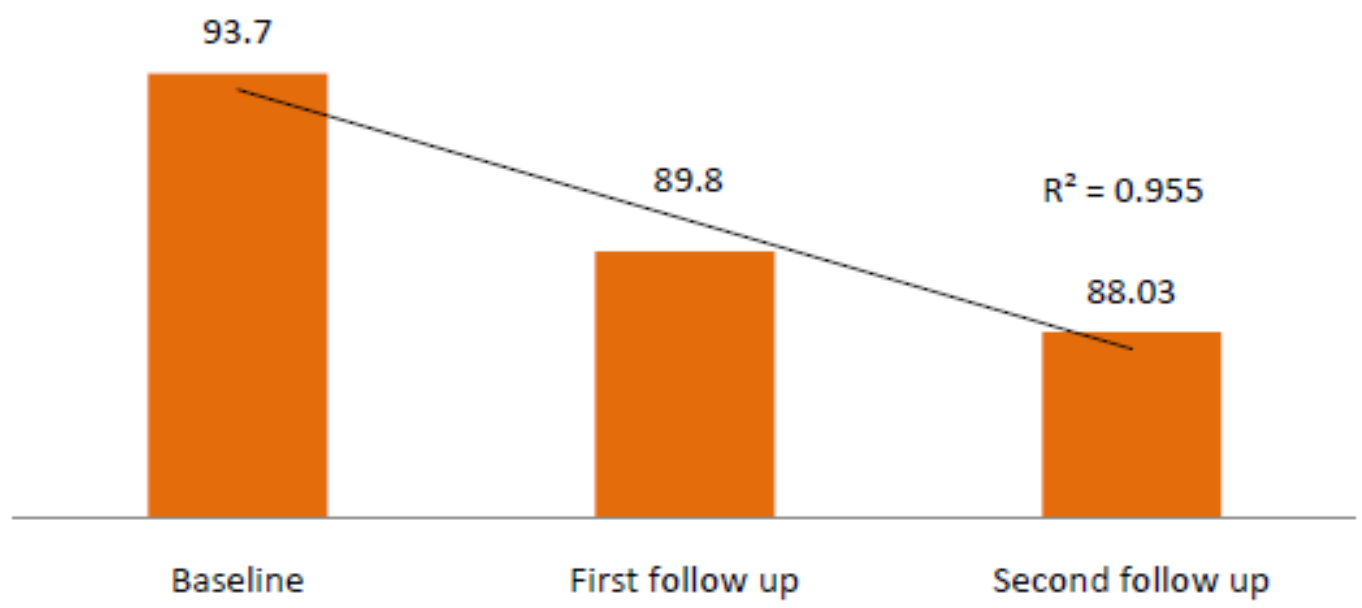

Figures 2. Pie chart, bar chart and linear chart: In the above charts we see the distribution of the compared blood creatinine scores at baseline, first follow up and second follow up after diabetes education among participants.

\section{Descriptive analysis of blood urea concentrations at baseline, first follow up and second follow up}

A sample of 648 patients with diabetes mellitus, who had participated in educational sessions concerning diabetes mellitus, was taken for study in order to see the effect of education on improving the outcomes of diabetes. The analysis performed for blood urea concentrations was done at baseline, at the first follow up and at the second follow up. The results are presented in Table 19, below. Briefly, the percentage of patients with normal blood urea concentrations of 1.2-3.0 mmol/l decreased from baseline (11.7\%), to the first follow up (8.6\%), to the second follow up (4.0\%). The percentage of patients with mildly increased levels of urea of $3.0-7.0 \mathrm{mmol} / \mathrm{l}$ decreased from baseline (50.5\%), to the first follow up (35.6\%), to the second follow up (16.4\%). The percentage of patients with moderately elevated levels of urea of 7.0-11.0 mmol/l decreased at each follow up from baseline (4.8\%), to the first follow up (3.4\%), to the second follow up (0.9\%). The percentage of patients with severely increased urea concentrations of $>11.0 \mathrm{mmol} / \mathrm{l}$ decreased at each follow up from baseline $(1.9 \%)$, to the first follow up $(0.9 \%)$, to the second follow up $(0.2 \%)$. The percentage of patients with missing values increased from baseline (31.0\%), to the first follow up (51.2\%), to the second follow up (78.2\%). 
Texila International Journal of Medicine

Volume 4, Issue 2, Dec 2016

Table 4. Descriptive analysis of blood urea at baseline, first follow up and second follow up

\begin{tabular}{lllllll}
\hline \multicolumn{3}{c}{ Baseline line } & \multicolumn{2}{l}{ First follow up } & \multicolumn{2}{l}{ Second follow up } \\
$\begin{array}{l}\text { Ranges of } \\
\text { Blood Urea }\end{array}$ & Frequency & $\begin{array}{l}\text { Percentages } \\
\%\end{array}$ & Frequency & $\begin{array}{l}\text { Percentages } \\
\%\end{array}$ & Frequency & $\begin{array}{l}\text { Percentages } \\
\%\end{array}$ \\
\hline $\begin{array}{l}\text { Normal } \\
\text { Blood Urea }\end{array}$ & 76 & 11.7 & 56 & 8.6 & 26 & 4.0 \\
$\begin{array}{l}1.2-3 \\
\text { mmol/l }\end{array}$ & & & & & & \\
Mildl Blood & 327 & 50.5 & 231 & 35.6 & 106 & 16.4 \\
$\begin{array}{l}\text { Urea 3-7 } \\
\text { mmol/l }\end{array}$ & & & & & & \\
moderate & 31 & 4.8 & 22 & 3.4 & 6 & .9 \\
$\begin{array}{l}\text { Blood Urea } \\
7-11 \text { mol/l }\end{array}$ & & & & & & \\
$\begin{array}{l}\text { Sever Blood } \\
\text { Urea }>11\end{array}$ & 12 & 1.9 & 6 & .9 & 1 & .2 \\
mmol/l & & & & & & \\
Not done & 201 & 31.0 & 332 & 51.2 & 507 & 78.2 \\
$\begin{array}{l}\text { Total } \\
\text { Missing }\end{array}$ & 647 & 99.8 & 647 & 99.8 & 646 & 99.7 \\
Total & 1 & .2 & 1 & .2 & 2 & .3 \\
\hline
\end{tabular}
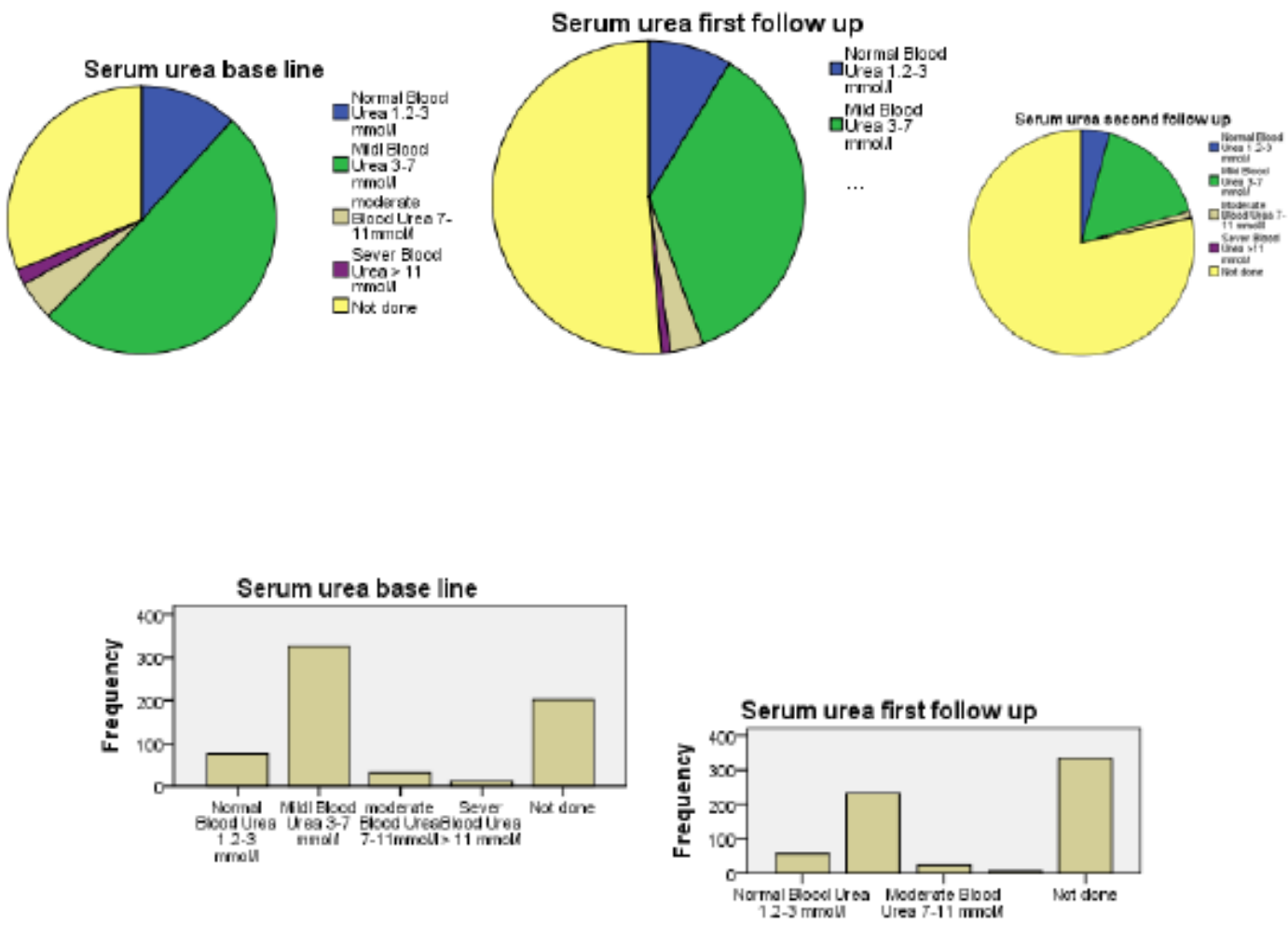
Effect of diabetic education on control of S.urea
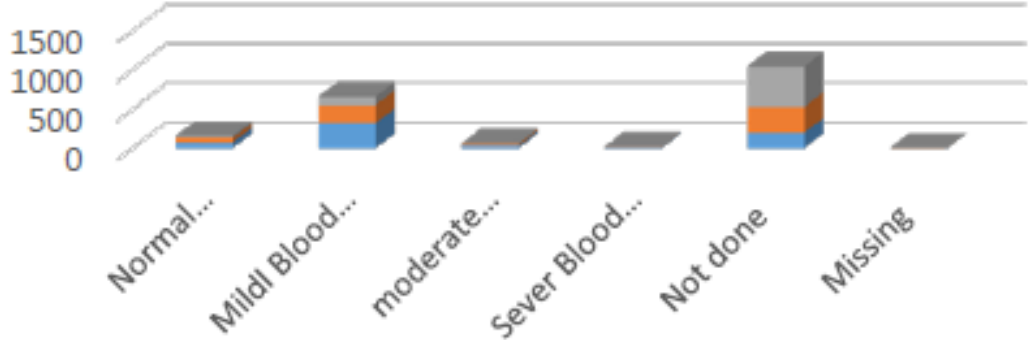

Base line $\square$ First fallow up $\quad$ Second fallow up

Effect of diabetic education on control of s.

urea

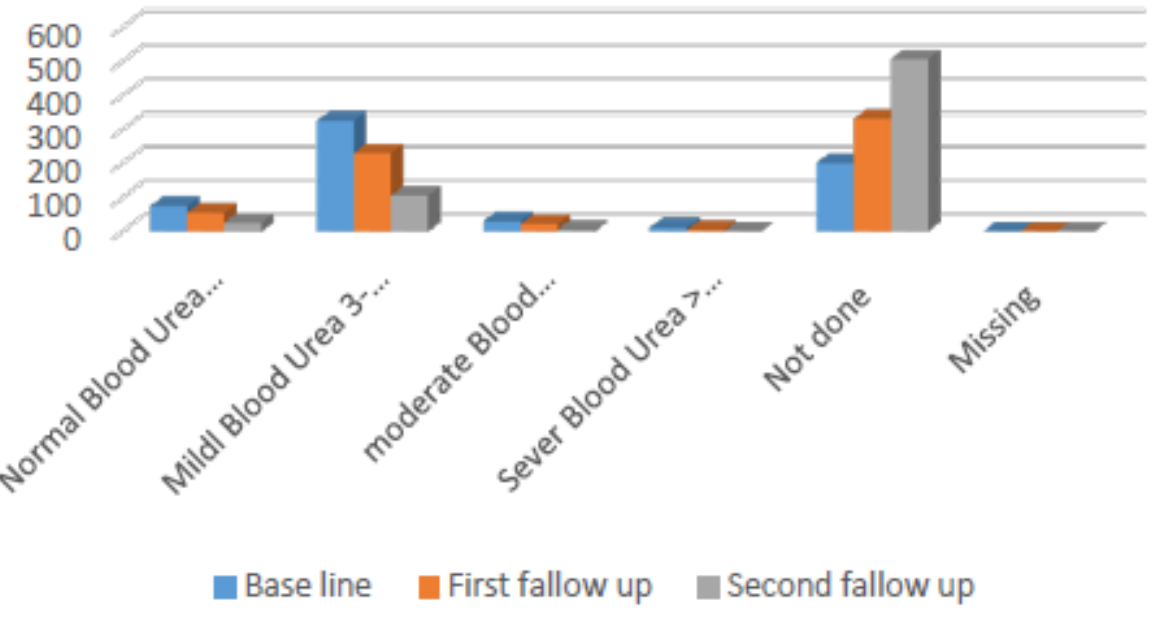

Effect of diabetic education on control of s.urea

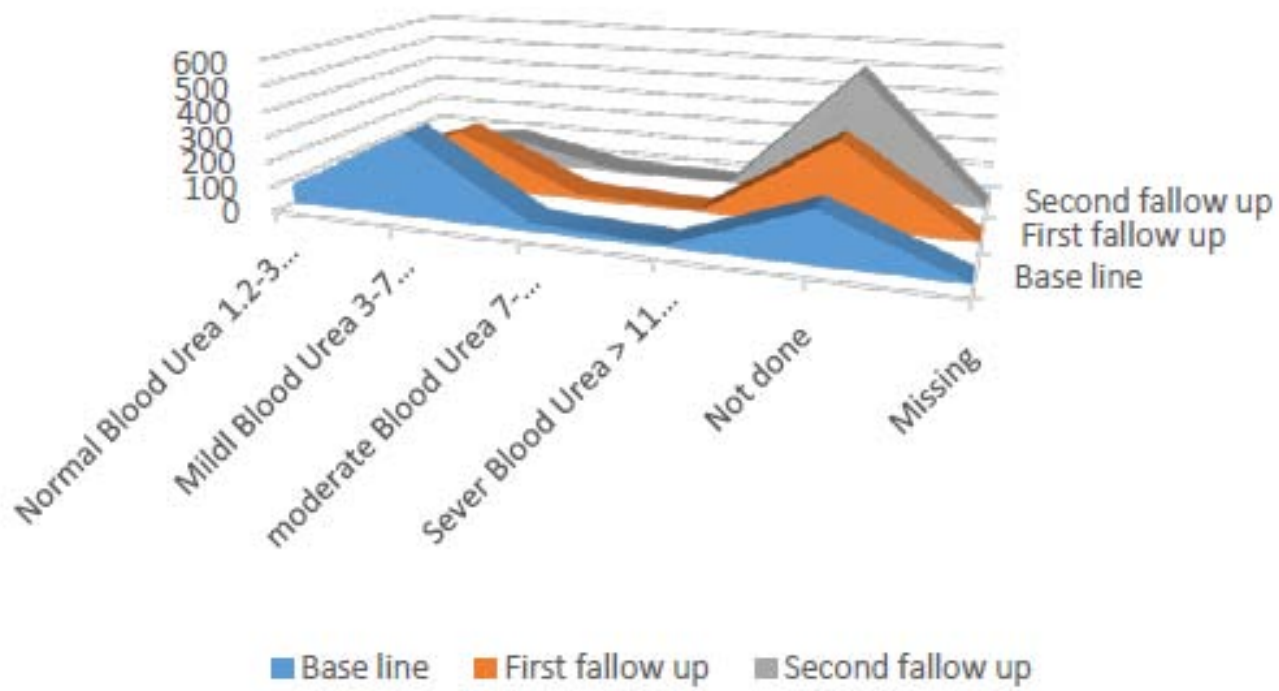




\section{Urea level at different follow up schedule}

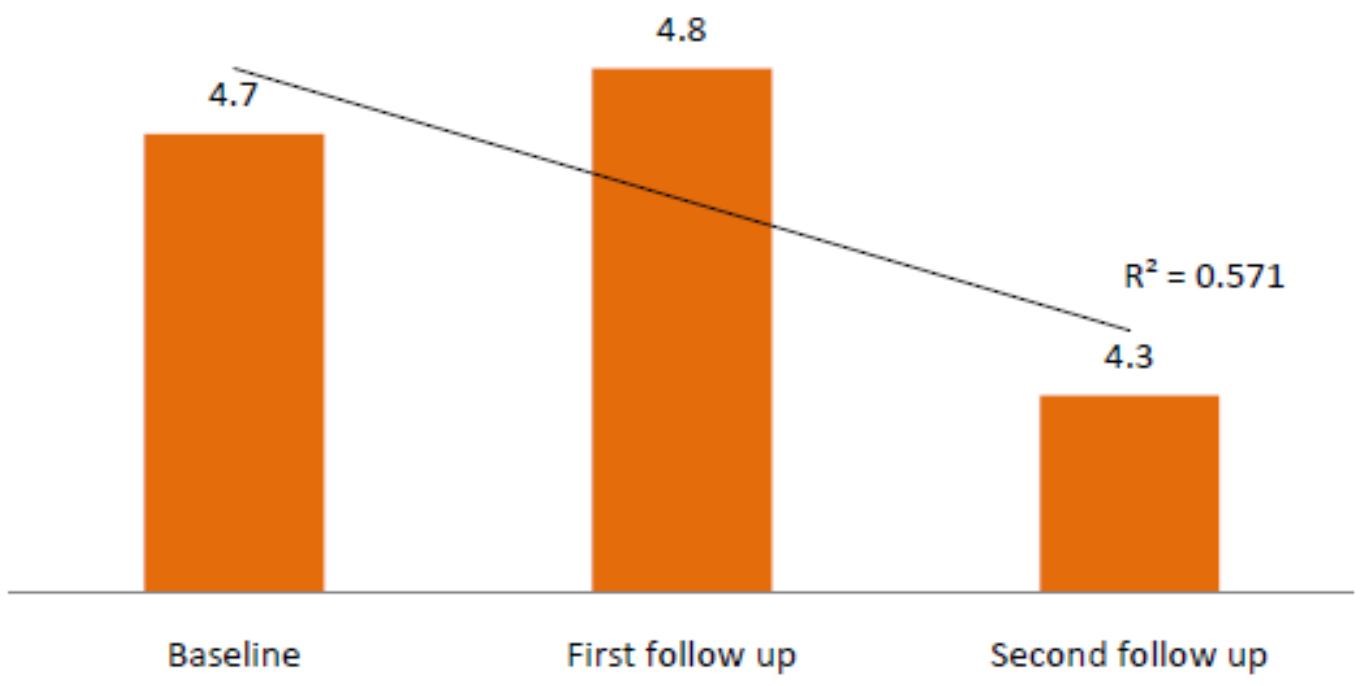

Figures 3. Pie chart, bar chart and linear chart: In the above charts we see the distribution of the compared blood urea scores at baseline, first follow up, and second follow up after diabetes education diabetes among participants.

Table 5. Descriptive analysis of fasting blood sugar at baseline, first follow up and second follow up

\begin{tabular}{lcccccc}
\hline & \multicolumn{2}{l}{ Baseline line } & \multicolumn{2}{l}{ First follow up } & \multicolumn{2}{l}{ Second follow up } \\
$\begin{array}{l}\text { Ranges of Blood } \\
\text { Sugar }\end{array}$ & $\begin{array}{l}\text { Frequen } \\
\text { cy }\end{array}$ & $\begin{array}{l}\text { Percentag } \\
\text { es \% }\end{array}$ & $\begin{array}{l}\text { Frequenc } \\
\text { y }\end{array}$ & $\begin{array}{l}\text { Percentag } \\
\text { es \% }\end{array}$ & $\begin{array}{l}\text { Frequen } \\
\text { cy }\end{array}$ & $\begin{array}{c}\text { Percent } \\
\text { ages \% }\end{array}$ \\
\hline $\begin{array}{l}\text { Hypoglycaemic }<3.9 \\
\text { mmol/dl }\end{array}$ & 31 & 4.8 & 27 & 4.2 & 33 & 5.1 \\
Normal 4-5.8 mmol/dl & 141 & 21.8 & 123 & 19.0 & 97 & 15.0 \\
Mild hyperglycaemic & 268 & 41.4 & 240 & 37.0 & 183 & 28.2 \\
5.9-11 mmol/dl & & & & & & \\
Moderate & 144 & 22.2 & 116 & 17.9 & 81 & 12.5 \\
hyperglycaemic 12-19 & & & & & & \\
mmol/dl & & & & & & \\
Sever hyperglycaemic & 51 & 7.9 & 29 & 4.5 & 21 & 3.2 \\
$>$ 20 mmol/dl & & & & & & \\
Problem laboratory & 1 & .2 & 12 & 1.9 & 29 & 4.5 \\
Not done & 10 & 1.5 & 99 & 15.3 & 202 & 31.2 \\
Total & 646 & 99.7 & 646 & 99.7 & 646 & 99.7 \\
Missing & 2 & .3 & 2 & .3 & 2 & .3 \\
Total & 648 & 100.0 & 648 & 100.0 & 648 & 100.0 \\
\hline
\end{tabular}




\section{Bar chart}
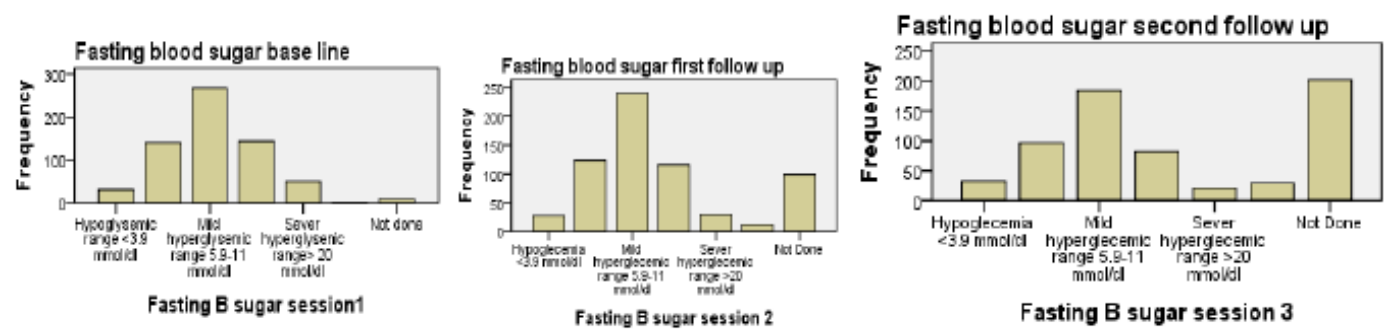

\section{Pie chart}

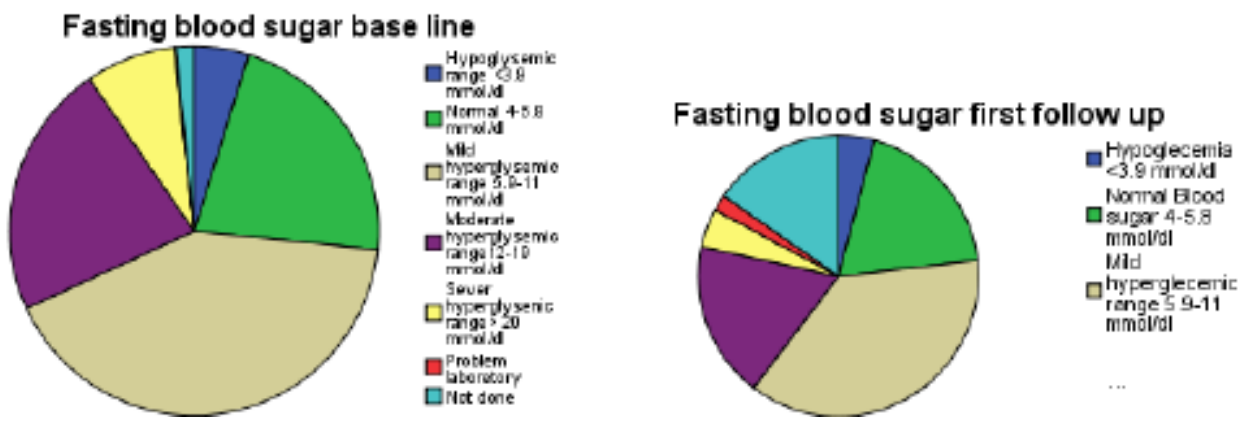

\section{Effect of education diabetes and control of}

b. Sugar

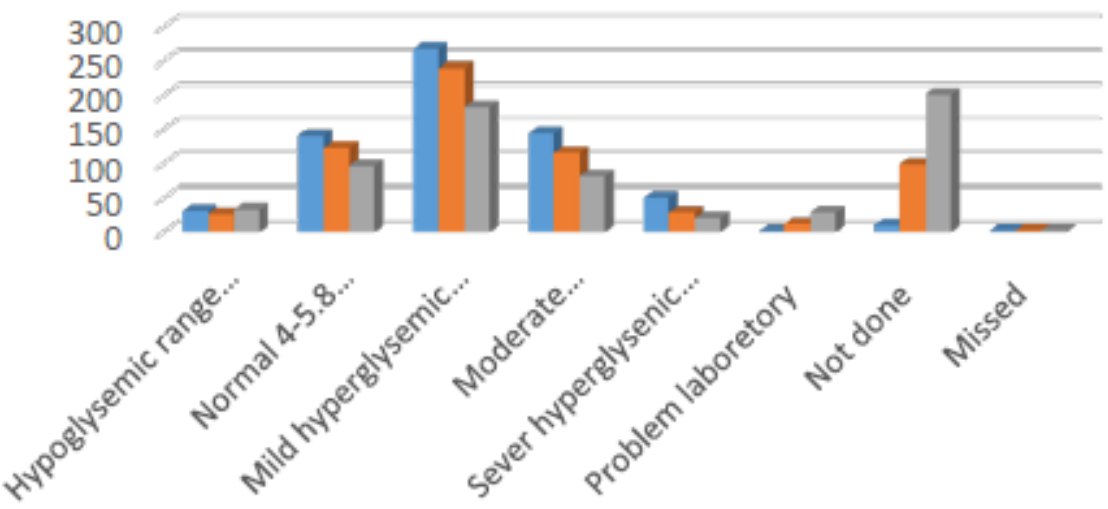

Base line Fallow up $1 \quad$ Fallow up 2 


\section{Effect of education of diabetes on control of}
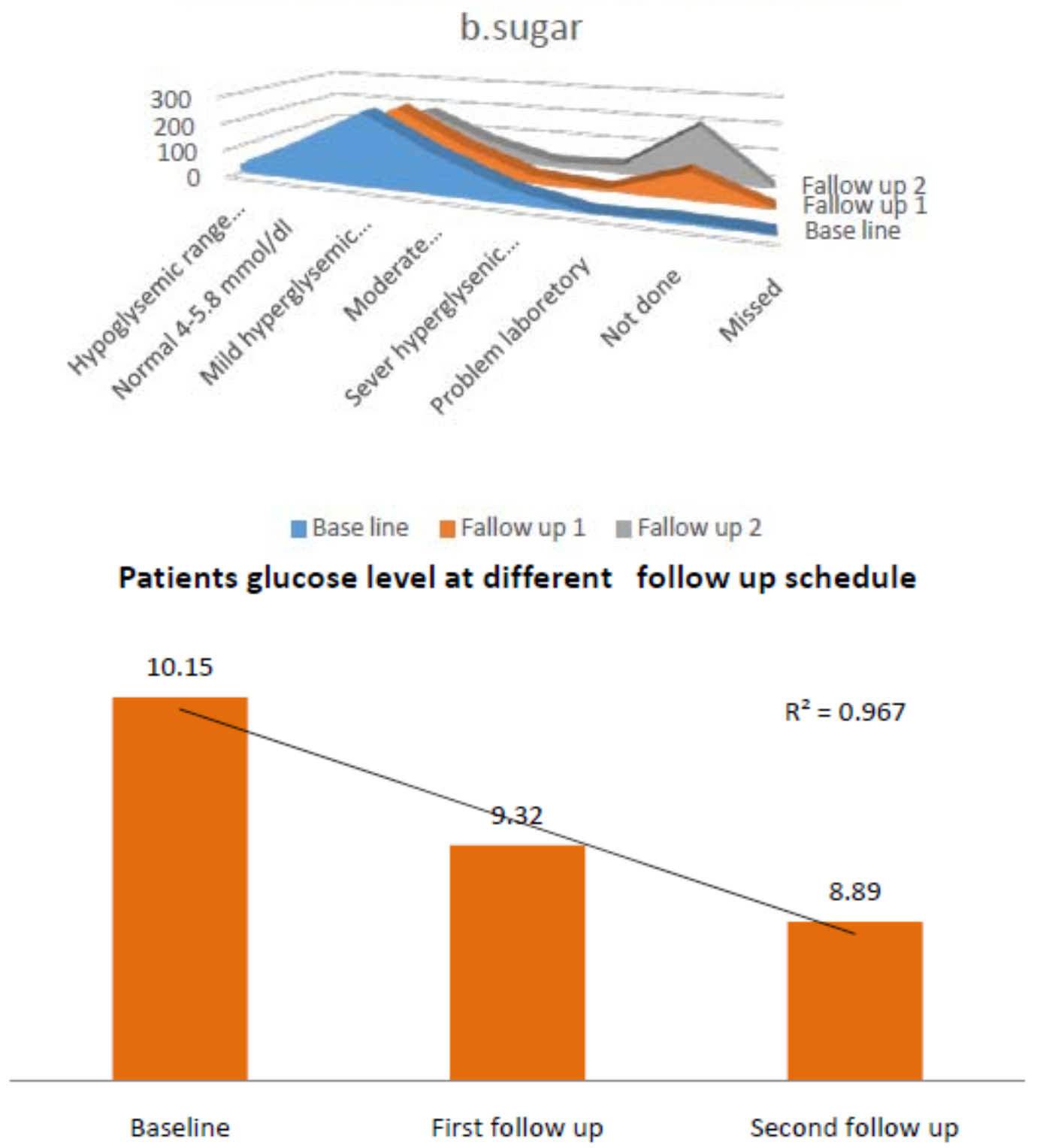

Figures 4. Pie chart, bar chart and linear chart: In the above charts we see the distribution of comparing fasting blood sugar scores at baseline, first follow up, and second follow up after diabetes education among participants.

\section{Summary table of descriptive statistics mean and standard deviation}

A sample of 648 patients with diabetes mellitus, who had participated in educational sessions regarding diabetes, was taken for study in order to determine the effect of education on improving outcomes in diabetes. The mean and standard deviation were calculated using plan coding, without grouping into categories. For the evaluation of the average systolic blood pressure baseline was $131.02 \mathrm{mmHg}(\mathrm{SD}=24.35 \mathrm{mmHg}$ ), and the average diastolic blood pressure baseline was $71.73 \mathrm{mmHg}(\mathrm{SD}=14.66 \mathrm{mmHg}$ ). The average systolic blood pressure at the first follow up was $121.98 \mathrm{mmHg}(\mathrm{SD}=22.01 \mathrm{mmHg})$ with an average diastolic blood pressure at the first follow up of $68.26 \mathrm{mmHg}(\mathrm{SD}=12.83 \mathrm{mmHg}$ ). The average systolic blood pressure at the second follow up was $120.95 \mathrm{mmHg}(\mathrm{SD}=19.95 \mathrm{mmHg}$ ), with an average diastolic blood pressure at the second follow up of $68.79 \mathrm{mmHg}(\mathrm{SD}=11.33 \mathrm{mmHg}$ ). As seen from baseline to the second follow up, a gradual decrease in both systolic and diastolic blood pressure was observed. When comparing the average serum creatinine concentrations from 
baseline to the second follow up, the baseline average was $93.62 \mathrm{umol} / \mathrm{l}(\mathrm{SD}=61.19 \mathrm{umol} / \mathrm{l})$, with an average of $89.83 \mathrm{umol} / \mathrm{l}(\mathrm{SD}=52.64 \mathrm{umol} / \mathrm{l})$ at the first follow up and $88.03 \mathrm{umol} / \mathrm{l}$ $(\mathrm{SD}=43.44 \mathrm{umol} / \mathrm{l})$ at the second follow up. Therefore, a gradual fall in serum creatinine from baseline to the second follow up was observed. When comparing the average blood urea concentration from baseline to the second follow up, the average urea concentration was found to be $4.66 \mathrm{mmol} / \mathrm{l}(\mathrm{SD}=4.14 \mathrm{mmol} / \mathrm{l})$ at baseline, $4.86 \mathrm{mmol} / \mathrm{l}(\mathrm{SD}=4.86 \mathrm{mmol} / \mathrm{l})$ at the first follow up and $4.30 \mathrm{mmol} / \mathrm{l}(\mathrm{SD}=1.80 \mathrm{mmol} / \mathrm{l})$ at the second follow up. Therefore, a small rise in the blood urea concentration was initially seen, which was then followed by a decrease in average concentration at the second follow up. The average fasting blood glucose concentration at baseline was $10.15 \mathrm{mmol} / \mathrm{dl}(\mathrm{SD}=6.00 \mathrm{mmol} / \mathrm{dl}$ ), at the first follow up 9.32 $\mathrm{mmol} / \mathrm{dl}(\mathrm{SD}=5.17 \mathrm{mmol} / \mathrm{dl}$ ), and at the second follow up $8.89 \mathrm{mmol} / \mathrm{dl}(\mathrm{SD}=5.19 \mathrm{mmol} / \mathrm{dl})$. Therefore, a gradual decrease in the fasting blood glucose concentration was observed from baseline to the second follow up.

Table 6. Descriptive statistics mean and standard Deviation of variables

\section{Descriptive Statistics Mean and standard Deviation}

\begin{tabular}{lll} 
& Mean & Std. Deviation \\
\hline Systolic blood pressure base line & $131.02 \mathrm{mmHg}$ & $24.35 \mathrm{mmHg}$ \\
Diastolic blood pressure base line & $71.73 \mathrm{mmHg}$ & $14.66 \mathrm{mmHg}$ \\
Systolic blood pressure first fallow up & $121.98 \mathrm{mmHg}$ & $22.01 \mathrm{mmHg}$ \\
Diastolic blood pressure first fallow up & $68.26 \mathrm{mmHg}$ & $12.83 \mathrm{mmHg}$ \\
Systolic blood pressure second follow up & $120.95 \mathrm{mmHg}$ & $19.95 \mathrm{mmHg}$ \\
Diastolic blood pressure second follow up & $68.79 \mathrm{mmHg}$ & $11.33 \mathrm{mmHg}$ \\
Blood glucose base line & $10.15 \mathrm{mmol} / \mathrm{dl}$ & $6.00 \mathrm{mmol} / \mathrm{dl}$ \\
Blood glucose first follow up & $9.32 \mathrm{mmol} / \mathrm{dl}$ & $5.17 \mathrm{mmol} / \mathrm{dl}$ \\
Blood glucose second follow up & $8.89 \mathrm{mmol} / \mathrm{dl}$ & $5.19 \mathrm{mmol} / \mathrm{dl}$ \\
Serum creatinine base line & $93.62 \mathrm{umol} / \mathrm{l}$ & $61.19 \mathrm{umol} / \mathrm{l}$ \\
Serum creatinine first follow up & $89.83 \mathrm{umol} / \mathrm{l}$ & $52.64 \mathrm{umol} / \mathrm{l}$ \\
Serum creatinine second follow up & $88.03 \mathrm{umol} / \mathrm{l}$ & $43.441 \mathrm{umol} / \mathrm{l}$ \\
Blood urea base line & $4.66 \mathrm{mmol} / \mathrm{l}$ & $4.14763 \mathrm{mmol} / \mathrm{l}$ \\
Blood urea first follow up & $4.86 \mathrm{mmol} / \mathrm{l}$ & $4.55 \mathrm{mmol} / \mathrm{l}$ \\
Blood urea second follow up & $4.30 \mathrm{mmol} / \mathrm{l}$ & $1.80 \mathrm{mmol} / \mathrm{l}$ \\
\hline
\end{tabular}

\section{ANOVA and regression analysis}

In order to examine the effect of diabetes education on the control of diabetes a multiple linear regression was conducted. This allowed an assessment of the control of fasting blood sugar concentrations at baseline as a dependent variable, with the independent variables of baseline blood pressure, blood urea, and creatinine.

The results of the linear regressions were significant $(\mathrm{F}(7,637)=2.44, \mathrm{P}=.018$, $\mathrm{R} 2=.026$ ), suggesting that fasting blood sugar levels at baseline and baseline blood pressure, accounted for $2.6 \%$ of variance in the control of fasting blood sugar levels. The individual predictors were then examined; it was found that fasting blood sugar level was a significant predictor for diabetic control $(\mathrm{B}=1.94, \mathrm{P}<.001)$, suggesting that for each unit increase in baseline fasting blood sugar concentration, the other variables of baseline urea increased by 1.94 units. Baseline post-test score was not found to be significant predictors for the control of fasting blood sugar levels. 
Texila International Journal of Medicine

Volume 4, Issue 2, Dec 2016

A post hoc Turkey test showed that baseline BMI when compared with the dependent variable, were significant $(\mathrm{P}=.05)$ at baseline and follow up for fasting blood sugar levels 


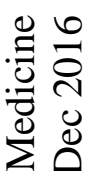

눙

코워

营是

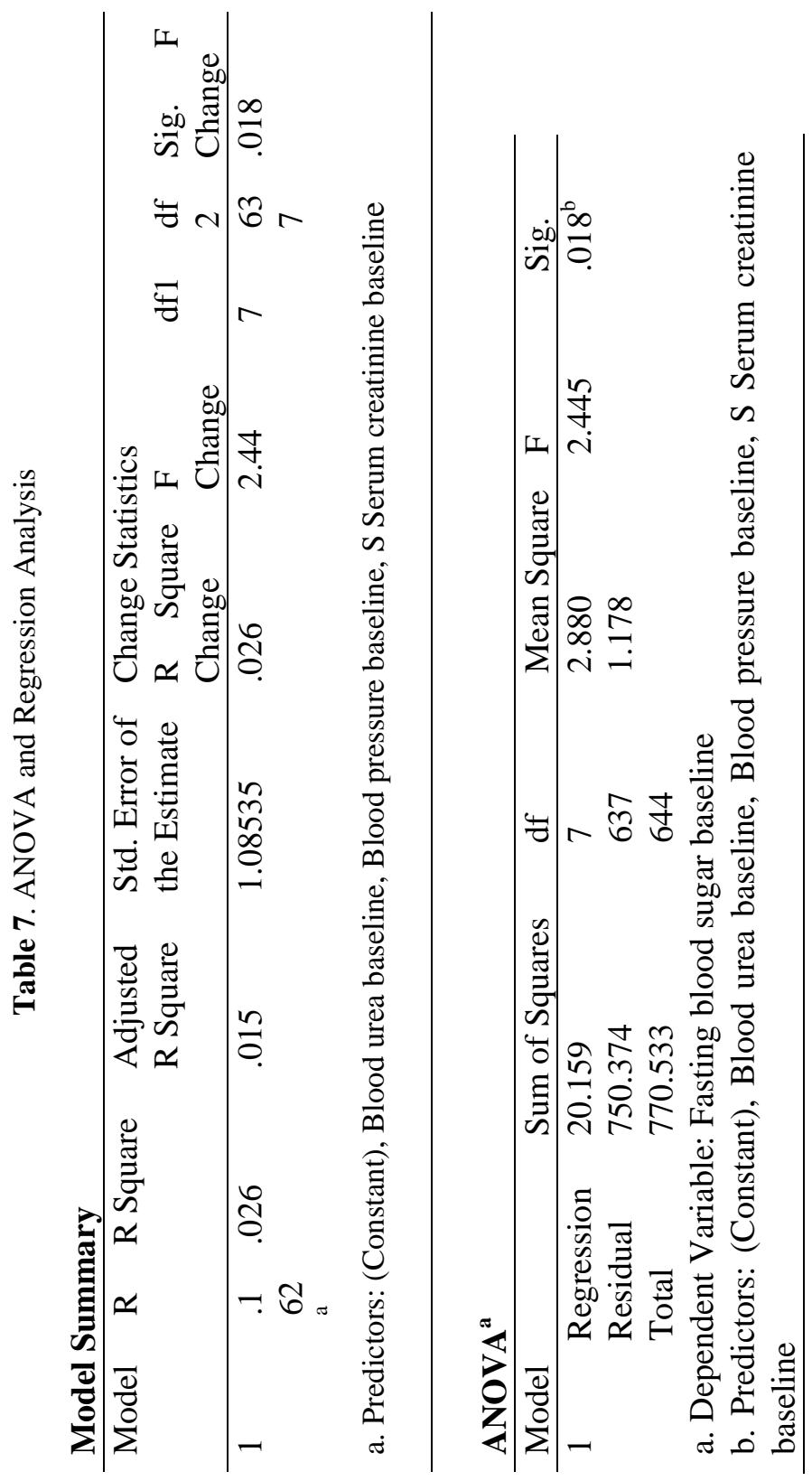


Texila International Journal of Medicine

Volume 4, Issue 2, Dec 2016

\section{Baseline session}

\section{First follow up}

In order to examine the effect of diabetes education on the control of diabetes mellitus and on the occurrence of complications, a multiple linear regression was conducted to assess the control of fasting blood sugar levels at the first follow up as a dependent variable with the independent variables blood pressure at the first follow up.

The result of the linear regression was significant $(F(7, .673)=52.34, P<.001$, $\mathrm{R} 2=.365$ ), suggesting that blood pressure, blood urea and creatinine accounted for $36.5 \%$ of the variance observed in the control of fasting blood sugar levels at the first follow up. The individual predictors examined further revealed that fasting blood sugar was a significant predictor for diabetic control $(\mathrm{B}=0.42, \mathrm{P}<.001)$, suggesting that for each unit increase at the first follow up of fasting blood sugar levels, the other variables of blood pressure, blood urea and creatinine, increased by 0.42 units at the first follow up. The post-test score was not found to be significant predictors for the control of fasting blood sugar.

A post hoc Turkey test showed that, at the first follow up, blood pressure, blood urea and creatinine, when compared with the dependent variable of blood sugar concentration at the first follow up were significant $(\mathrm{P}=.005)$. 


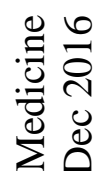

ชั

콣

高鿷

厗

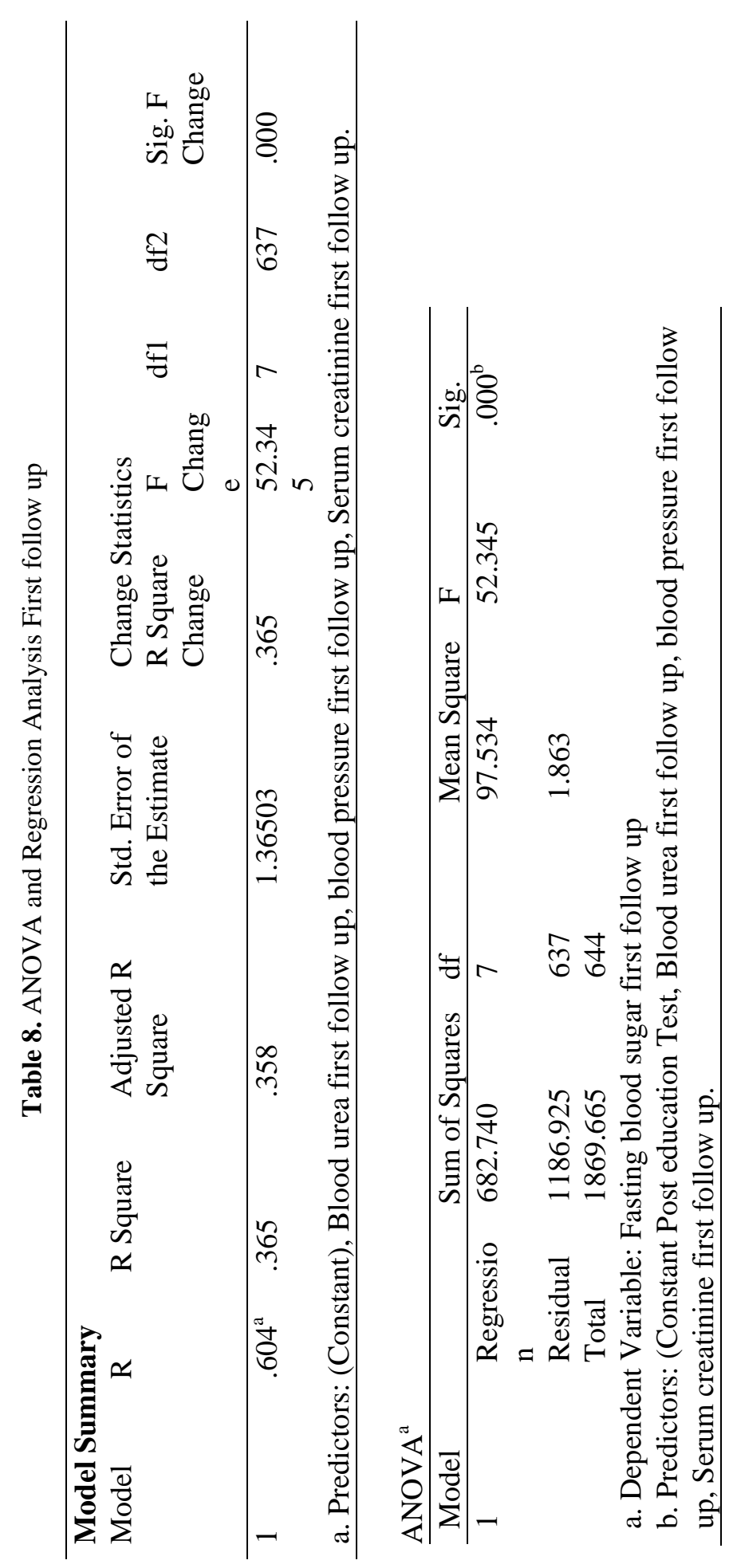


Texila International Journal of Medicine

Volume 4, Issue 2, Dec 2016

\section{Second follow up}

In order to examine the effect of diabetes education on diabetes control and on the incidence of complications, a multiple linear regression was conducted. This allowed the assessment of the control of fasting blood sugar levels at the second follow up as a dependent variable with the independent variables at the second follow up of blood pressure, blood urea and creatinine.

The results of the linear regression were significant $(F(8,632)=66.37, P<.001$, $\mathrm{R} 2=.450$ ), suggesting that at the second follow up, blood pressure, blood urea and creatinine accounted for $45 \%$ of the variance in the control of fasting blood sugar levels. The individual predictors examined further identified fasting blood sugar as a significant predictor for diabetic control $(\mathrm{B}=-.165, \mathrm{P}<.001)$, suggesting that for each unit decrease at the second follow up of fasting blood sugar concentration, the other variables of blood pressure, blood urea and creatinine, decreased by -.165 units at the second follow up.

A post hoc Turkey test showed that, at the second follow up, blood pressure, blood urea and creatinine when compared with the dependent variable of fasting blood sugar concentration at the second follow up, were significant $(\mathrm{P}=.005)$. 


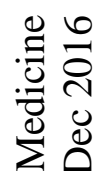

ชิ

苂氙

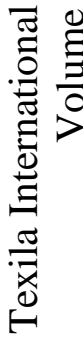

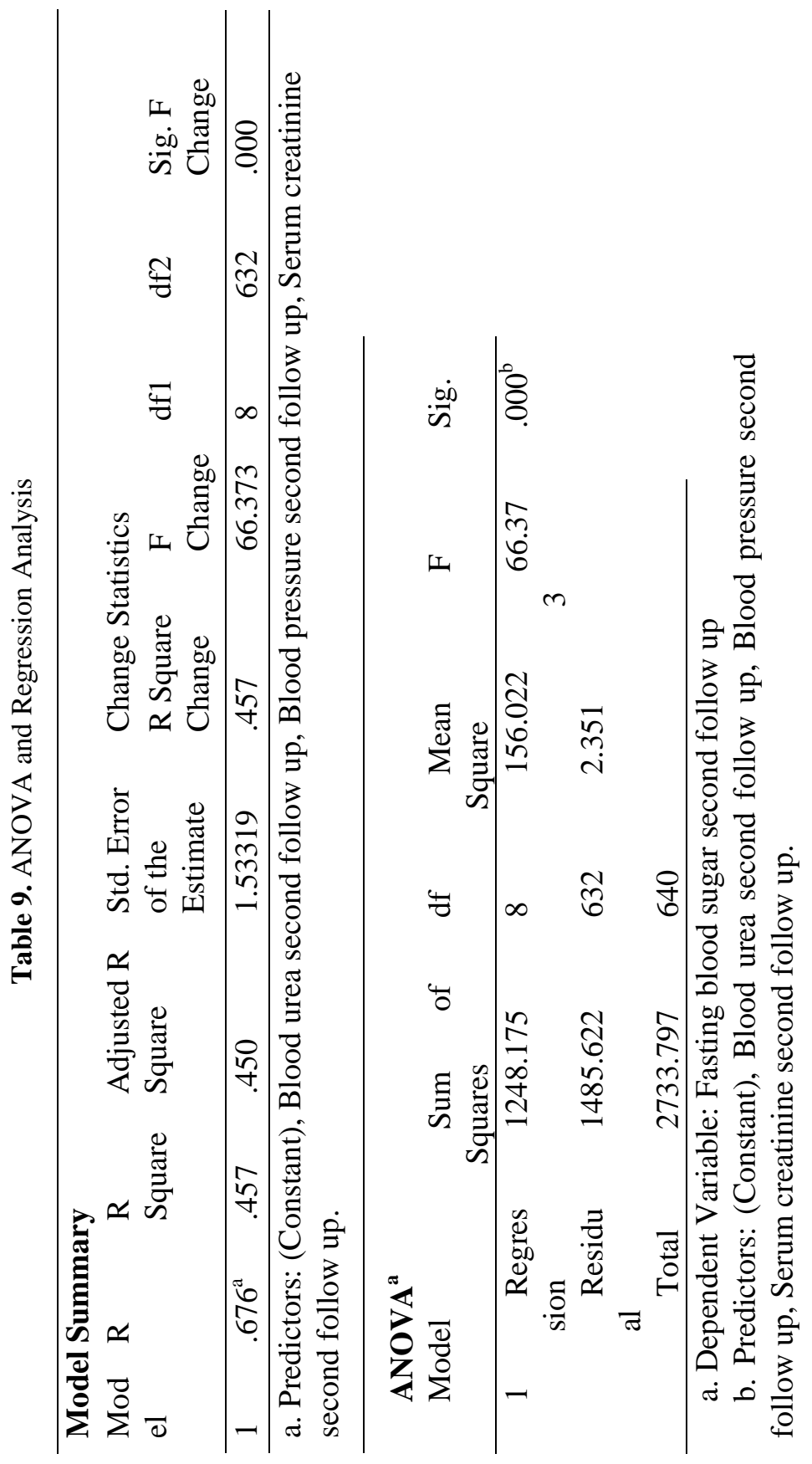


Texila International Journal of Medicine

Volume 4, Issue 2, Dec 2016

\section{Summary of main findings}

A sample of 648 participants was taken for this study. This study was conducted on regular patients of the diabetic outpatient department of the Central Hospital of Nampula. The study investigated the effects of three sessions of the diabetes education program (baseline, first follow-up and second follow-up) on each patient at one-month intervals. The inclusion criteria for participating in the diabetes education program dictated that patients should be in the OPD, willing to participate in the education sessions and willing to give consent to be included in the study. Participants were excluded if they had already completed three sessions of education or if they lived in a district that made it impossible for them to return within one month to the next education session. Amongst the group instructors were a diabetologist, dietician, psychologist, physiotherapist, and diabetic nurse. There was a pre-test questionnaire that aimed to assess the existing knowledge of diabetes before starting the baseline education session. The same questions were asked after the completion of the second follow-up education session. There were various variables to assess from baseline to second follow up education session. The variables were assessed age groups, body mass index, and fasting blood sugar.

Table 10. Regression, ANOVA analysis and post hoc Turkey test:

\begin{tabular}{|c|c|}
\hline \multicolumn{2}{|l|}{ Base line } \\
\hline linear regression & $\begin{array}{l}\text { Significant } \mathrm{F}(7,637)=2.44, \mathrm{P}<=.018, \mathrm{R} 2= \\
.026\end{array}$ \\
\hline The individual predictor & $\begin{array}{l}\mathrm{B}=1.94 \mathrm{P}<.000 \text { suggest that for every one } \\
\text { unit increase of baseline fasting blood sugar, } \\
\text { the other variables baseline increase } 1.94 \\
\text { Unit, }\end{array}$ \\
\hline Post hoc Turkey test & $\begin{array}{l}\text { Baseline compared with dependent variable } \\
\text { baseline follow up fasting blood sugar } \\
\text { significant } \mathbf{P}<\mathbf{. 0 5} \text {. }\end{array}$ \\
\hline \multicolumn{2}{|l|}{ First follow up } \\
\hline linear regression & $\begin{array}{l}\text { significant, } \mathrm{F}(7, .673)=52.34, \mathrm{P}<=.000, \mathrm{R} 2= \\
.365 \mathrm{R} 2=.365\end{array}$ \\
\hline The individual predictor & $\begin{array}{l}\mathrm{B}=0.42 \mathrm{P}<.001 \text { suggest that for every one } \\
\text { unit increase of first follow up fasting blood } \\
\text { sugar, the other variables first follow up } \\
\text { Blood pressure, blood creatinine and urea } \\
\text { increase } 0.42 \text { Unit, }\end{array}$ \\
\hline Post hoc Turkey test & $\begin{array}{l}\text { Blood pressure, blood creatinine and urea } \\
\text { compared with dependent variable first } \\
\text { follow up blood sugar are significant } \mathbf{P}< \\
\mathbf{. 0 0 5} \text {. }\end{array}$ \\
\hline \multicolumn{2}{|l|}{ First follow up } \\
\hline linear regression & $\begin{array}{l}\text { significant, } \mathrm{F}(7, .673)=52.34, \mathrm{P}<=.000, \mathrm{R} 2= \\
.365 \mathrm{R} 2=.365\end{array}$ \\
\hline
\end{tabular}




\begin{tabular}{|c|c|}
\hline The individual predictor & $\begin{array}{l}\mathrm{B}=-.165 \mathrm{P}<.001 \text { every one unit decrease of } \\
\text { second follow up fasting blood sugar, the } \\
\text { other variables second follow up Blood } \\
\text { pressure, blood creatinine and decrease }-.165 \\
\text { Unit } \\
\text { Blood pressure, blood creatinine and urea } \\
\text { compared with dependent variable first } \\
\text { follow up blood sugar are significant } \mathbf{P}< \\
\mathbf{. 0 0 5} \text {. }\end{array}$ \\
\hline \multicolumn{2}{|l|}{ Second follow up } \\
\hline linear regression & $\begin{array}{l}\text { significant, } \mathrm{F}(8,632)=66.37, \mathrm{P}<=.000, \mathrm{R} 2= \\
.450\end{array}$ \\
\hline The individual predictor & $\begin{array}{l}\mathrm{B}=0.42 \mathrm{P}<.001 \text { suggest that for every one } \\
\text { unit increase of first follow up fasting blood } \\
\text { sugar, the other variables first follow up } \\
\text { Blood pressure, blood creatinine and urea } \\
\text { increase } 0.42 \text { Unit, }\end{array}$ \\
\hline Post hoc Turkey test & $\begin{array}{l}\text { Second follow up Blood pressure, blood } \\
\text { creatinine compared with dependent variable } \\
\text { second follow up fasting blood sugar are } \\
\text { significant } \mathbf{P}<\mathbf{. 0 0 5} \text {. }\end{array}$ \\
\hline
\end{tabular}

\section{Discussion}

The present study found that educational intervention was highly effective in controlling blood pressure, as these had significantly decreased from baseline at the second patient follow up visit. Metabolic control (blood sugar, urea and creatinine) also showed a significant positive improvement from baseline at the second follow up visit. The knowledge provided by the education helped the participants to improve and change their lifestyle, especially their dietary and exercise habits, their psychological adjustment and their attitude to living with diabetes.

Similar studies have previously been performed, with some comparable findings being reported. Newly diagnosed diabetic patients need self-management education, as this helps to increase their level of knowledge of diabetes and to provide them with skills to manage their diabetes life long, as it is a chronic condition (American Diabetes Association, 2014). A Cochrane review (Deakin, 2009) concluded that a reduction in blood sugar concentrations, and increased knowledge of diabetes. A Cochrane review (Deakin, 2009) concluded that through group education of diabetes patients get motivated, start adherence to treatment and understand diabetes. Meta analyses and the outcome of various studies have shown positive impacts after receiving diabetes education, and enhanced knowledge of diabetes has been presented by Ricci-Cabello et al. (2014). In order to promote diabetes awareness, self-care behaviors can be useful. Choi et al. (2016) described innovative strategies for the improvement of diabetic control and glycemic improvement in Chinese patients through the continuing education of diabetes mellitus during patient examination and by increasing family involvement via diabetic knowledge. Mollaoğlu et al. (2009) emphasized repeated diabetic education sessions to control and improve metabolic parameters. Salinero-Fort et al. (2011), using experimental and control groups regarding diabetes education. Salinero-Fort et al., 
(2011), taken an experimental and control group, pre and post education of diabetes, effects which showed reduced in Systolic and diastolic blood pressure. Pereira et al., (2014), explained that education of diabetes assists in controlling metabolic control, reduction of blood pressure in the intervention group.

\section{Conclusion}

Diabetes mellitus is a chronic and progressive disease, the prevalence of which is rapidly increasing. Uncontrolled diabetes mellitus may cause severe and irreversible untreatable complications, such as cardiovascular disease, retinopathy, nephropathy and cataract development. There is therefore a need to control anthropometric and metabolic parameters within an acceptable range in order to avoid the development of complications.

Currently, it is not only wealthy countries that have a high prevalence of diabetes mellitus; low and mid-level economic counties are also progressively showing an increase in the prevalence of diabetes mellitus. This includes Mozambique, which shows a progressive increase in the number of patients with diabetes mellitus due to the lack of a healthy diet, a sedentary life style and urbanization. Regarding patients with diabetes mellitus in a central hospital in Nampula, it was recognized that there was a need to organized education concerning diabetes, such as regarding the diabetic diet, increasing patient knowledge of diabetes to avoid the risks of complications, physical activity and its importance, and the psychological motivation to live with diabetes.

Diabetes education was performed with general and specific groups of patients according to the needs of the patients, the complications of the diabetes mellitus and other diseases associated with them. Three education sessions were organized, at an interval of one month (baseline, first follow up and second follow up). Each participant was evaluated in each session regarding their blood pressure, blood sugar, urea and creatinine. The statistical analysis showed strong significantly positive effects on controlling each of these parameters.

\section{Motivational quote}

"Exercise and diet can help prevent or even totally reverse metabolic conditions like diabetes and cardiovascular disease - only thing is you've got to catch them young... You know, while these conditions are still of 'impressionable minds'!"

- Deepak 'The Fitness Doc' Hiwale

There is currently a need to design a national policy and program for diabetes education. Clinicians and health educators should continue to reemphasize that patients with diabetes mellitus make healthy behavioral changes in order to control their diabetes and reduce the occurrence of complications.

The limitations of this study include that some of the diabetic patients used traditional medications, some did not adhere to treatment, and some were lost to follow up, all of which can cause uncontrollable diabetes and increase the incidence of complications. Patients were very interested in taking medicine free of charge in a government hospital. Limitations were also found here, such as the intermittent non-availability of the results of blood sugar, urea and creatinine results due to a lack of laboratory reagents. Patients who lived district, distance from the hospital, were not able to regularly attend three education sessions. Patients were more interested in obtaining medication than on lifestyle modification. Patients were generally from a poor or lower income group, and were unable to buy the recommended food. It was also noted that some patients had an insufficient economic condition to take small and frequent meals. Some of the patients presented with a delayed diagnosis, with irreversible complications.

One of the strengths of this study is that patients, at the commencement of educational sessions, were encouraged to participate and to bring laboratory results and other activities to the follow up sessions by reminding them that they would receive prescription medicine at the end of the successful completion of all of the essential activities involved in the education sessions. This encouraged patients to take a further interest in the study, and the majority of 
these patients then implemented the required changes in their lives and achieved positive significant outcomes in controlling their diabetes.

\section{Contribution to knowledge}

This study adds to the current body of knowledge regarding lifestyle modification and patient knowledge of diabetes. The education provided in this study allowed patients to understand diabetes and to control and minimize related complications.

\section{Suggestion for future research}

However, a need remains to involve other departments in future studies, for example emergency and intensive care medicine, district hospitals and effect of education of diabetes of family members to control the diabetic of patient, in order to see effect of education of diabetes to improve the knowledge of diabetes in public for primary prevention of diabetes in society.

\section{References}

[1]. Association, A. D. (2002). Standards of medical care for patients with diabetes Mellitus. Diabetes Care, 25(suppl 1), 33-49. doi:10.2337/diacare.25.2007.S33In-line Citation:(Association, 2002)

[2]. Abdullah M., 2012, 'Effects of the diabetes education program on metabolic Control among Saudi type 2 diabetic patients', Pakistan Journal Medical Science 2012 Vol. 28 No. 5 www.pjms.com.pk 925930 (2012), viewed pjms.com.pk/index.php/pjms/article/view File//954

[3]. Braun, A., Sämann, A., Kubiak, T., Zieschang, T., Kloos, C., Müller, U.A., Oster, P., Wolf, G. and Schiel, R. (2008) 'Effects of metabolic control, patient education and initiation of insulin therapy on the quality of life of patients with type 2 diabetes mellitus', Patient Education and Counseling, 73 (1), pp. 50-59. doi: 10.1016/j.Pec.2008.05.005. In-text citations: (Braun et al., 2008)

[4]. Burke, S., Sherr, D. and Lipman, R. (2014) 'Partnering with diabetes educators to improve patient outcomes', Diabetes, metabolic syndrome and obesity: targets and therapy., 7, pp. 45-53. In-text citations: (Burke, Sherr, and Lipman, 2014)

[5]. BJMP (2009) Impact of diabetes education and peer support group on the metabolic parameters of patients with diabetes Mellitus (type 1 and type 2). Available at: http://www.bjmp.org/content/impactdiabetes-education-and-peer-support-group-metabolic-parameters-patients-diabetes-mellitus-type-1-

and-type-2 (Accessed: 14 August 2016). In-text citations: (BJMP, 2009)

[6]. Chrvala, C., Sherr, D. and Lipman, R. (2015) 'Diabetes self-management education for adults with type 2 diabetes mellitus: A systematic review of the effect on glycemic control', Patient education and counseling., 99 (6), pp. 926-43. In-text citations: (Chrvala, Sherr, and Lipman, 2015)

[7]. Choi, T.S.T., Davidson, Z.E., Walker, K.Z., Lee, J.H. and Palermo, C. (2016) 'Diabetes education for Chinese adults with type 2 diabetes: A systematic review and meta-analysis of the effect on glycemic control', Diabetes Research and Clinical Practice, 116, pp. 218-229. doi: 10.1016/j.diabres.2016.04.001.In-text citations: (Choi et al., 2016)

[8]. Center, J. D. (2016, August 14). Diabetes education: Why it's so crucial to care. Retrieved August 14, 2016, from http://www.joslin.org/info/diabetes_education_why_its_so_crucial_to_care.htmlIn-line Citation: (Center, 2016)

[9]. Diabetes Education Study Group (1977) History. Available at: http://www.desg.org/desg/about/history/ (Accessed: 14 August 2016). In-text citations: (DESG, 1977) [10]. Disclaimer, I. D. F. (2015). Mozambique. Retrieved August 29, 2016, from http://www.idf.org/membership/afr/mozambiqueIn-line Citation:(Disclaimer, 2015)

[11]. Ellis, S.E., Speroff, T., Dittus, R.S., Brown, A., Pichert, J.W. and Elasy, T.A. (2004) 'Diabetes patient education: A meta-analysis and meta-regression', Patient Education and Counseling, 52 (1), pp. 97-105. doi: 10.1016/S0738-3991(03)00016-8. In-text citations: (Ellis et al., 2004)

[12]. 5.5 general diabetes self-management and education (2016) Available at: https://www.icsi.org/guideline_sub-pages/diabetes/55_general_diabetes_self-

management_and_education/ (Accessed: 14 August 2016).In-text citations: (5.5 general diabetes selfmanagement and education, 2016) 
Texila International Journal of Medicine

Volume 4, Issue 2, Dec 2016

[13]. Kent, D., Melkus, D., Stuart, P., McKoy, J., Urbanski, P., Boren, S., Coke, L., Winters, J., Horsley, N., Sherr, D. and Lipman, R. (2013a) 'Reducing the risks of diabetes complications through diabetes self-management education and support', Population health management., 16 (2), pp. 74-81. In-text citations: (Kent et al., 2013a)

[14]. Moattari, M., Ghobadi, A., Beigi, P. and Pishdad, G. (2012) 'Impact of self management on metabolic control indicators of diabetes patients', Journal of Diabetes \& Metabolic Disorders, 11 (1), p. 6. doi: 10.1186/2251-6581-11-6. In-text citations: (Moattari et al., 2012)

[15]. Mollaoğlu, M. and Beyazıt, E. (2009) 'Influence of diabetic education on patient metabolic control’, Applied Nursing Research, 22 (3), pp. 183-190. doi: 10.1016/j.apnr.2007.12.003. In-text citations: (Mollaoğlu and Beyazıt, 2009)

[16]. MakkiAwouda, F., Elmukashfi, T. and Al-Tom, H. (2014) 'Effects of health education of diabetic patient's knowledge of diabetic health centers, Khartoum State, Sudan: 2007-2010', Global journal of health science, 6 (2), pp. 221-6. In-text citations: (MakkiAwouda, Elmukashfi, and Al-Tom, 2014)

[17]. Merakou, K., Knithaki, A., Karageorgos, G. and Theodoridis, D. (2015) 'Group patient education: Effectiveness of a brief intervention in people with type 2 diabetes mellitus in primary health care in Greece: A clinically controlled trial', Health Education Research, 30 (2), pp. 223-232. doi: 10.1093/her/cyv001.In-text citations: (Merakou et al., 2015)

[18]. Mash, B., Levitt, N., Steyn, K., Zwarenstein, M. and Rollnick, S. (2012) 'Effectiveness of a group diabetes education program in underserved communities in South Africa: Pragmatic cluster randomized control trial', BMC Family Practice, 13 (1). doi: 10.1186/1471-2296-13-126. In-text citations: (Mash et al., 2012)

[19]. Mendes, G., Nogueira, J., Reis, C., Meiners, D. and Dullius, J. (2016) 'Diabetes education program with emphasis on physical exercise promotes significant reduction in blood glucose, HbA1c and triglycerides in subjects with type 2 diabetes: A community-based quasi-experimental study', The Journal of sports medicine and physical fitness., In-text citations: (Mendes et al., 2016)

[20]. Norris, S., Lau, J., Smith, S., Schmid, C. and Engelgau, M. (2002) 'Self-management education for adults with type 2 diabetes: A meta-analysis of the effect on glycemic control', Diabetes care., 25 (7), pp. 1159-71. In-text citations: (Norris et al., 2002)

[21]. Pereira, D.A., Ma, N., Costa, S.C., Luíza, A., Sousa, L., César, P., Jardim, V., Sanches, L. and Jardim, S. (2014) 'Effect of an educational intervention on the metabolic control of people with type 2 diabetes', Journal of Diabetes Nursing, 18. In-text citations: (Pereira et al., 2014)

[22]. Ricci-Cabello, I., Ruiz-Pérez, I., Rojas-García, A., Pastor, G., Rodríguez-Barranco, M. and Gonçalves, D.C. (2014)'Characteristics and effectiveness of diabetes self-management educational programs targeted to racial/ethnic minority groups: A systematic review, meta-analysis and metaregression', BMC Endocrine Disorders, 14 (1), p. 60. doi: 10.1186/1472-6823-14-60. In-text citations (Ricci et al., 2014)

[23]. Retrieved August 29, 2016, from https://en.wikipedia.org/.../Geography_of_Mozambi. NDEP program overview. (2016, June 24). Retrieved August 29, 2016, from https:/www.niddk.nih.gov/health-information/health-communication-programs/ndep/about-ndep/ndepoverview/Pages/ndep-overview.aspxIn-line Citation:(“NDEP program overview,” 2016)

[24]. Salinero-Fort, M., Santa, C., Arrieta-Blanco, F., Abanades-Herranz, J., Martín-Madrazo, C., Rodés-Soldevila, B. and Burgos-Lunar, de (2011) 'Effectiveness of PRECEDE model for health education on changes and level of control of HbA1c, blood pressure, lipids, and body mass index in patients with type 2 diabetes mellitus', BMC public health., 11. In-text citations: (Salinero-Fort et al., 2011)

[25]. Tidy, C. (2014b) Diabetes education and self-management programs. Patient. Available at: http://patient.info/doctor/diabetes-education-and-self-management-programmes (Accessed: 14 August 2016). In-text citations: (Tidy, 2014b)

[26]. zareban, I., Niknami, S. and Rakhshani, F. (2013) 'The effect of the self-efficacy education program on reducing blood sugar levels in patients with type 2 diabetes', Health Education \& Health Promotion, 1 (1), pp. 67-79. In-text citations: (zareban, Niknami, and Rakhshani, 2013) 